$\xi=$ 不

\title{
Prediction of pore pressure using well logs and seismic data in Fabi Field, Onshore Niger delta, Nigeria
}

\author{
Aniwetalu Emmanuel U *, Anakwuba Emmanuel, Ilechukwu Juliet N, Chidozie Okoye \\ Department of Geological Sciences, NnamdiAzikwe University, Awka, Nigeria \\ *Corresponding author E-mail:emmymega3@yahoo.com
}

\begin{abstract}
The variations of pore pressure in Fabi Field Onshore Niger delta have been investigated using well log and seismic data. The both data were calibrated to ensure reasonable match in depth. Zones of overpressure were predicted from the well logs based on the deviations of petrophysical measurement from normal compaction trends. The lateral variations of the overpressure were delineated from seismic data through elastic impedance inversion. Overpressure cube was delineated from the inverted volumes through points of picked horizons. The results of the study revealed overpressure occurrence in well logs at depth level of $8625 \mathrm{ft}$ to $9000 \mathrm{ft}$. The elastic impedance inversion presents overpressure variations beyond well control point at the depth level of about 1940-1140ms corresponding to very high impedance value of about $25540-27067 \mathrm{ft} / \mathrm{s} * \mathrm{~g} / \mathrm{cc}$. The area extents of the positive anomalies (increase in elastic impedance) are mostly consistent with overpressure zones. Overpressure zones were also estimated from the seismic data between $1560 \mathrm{~ms}-1600 \mathrm{~ms}$ within the TRK-1 and TRK-2 horizon which also correspond to the well control points ( $8625 \mathrm{ft}$ to nearly $9000 \mathrm{ft}$ ). The velocity and density crossplots revealed that undercompaction is the main overpressure generating mechanism in Fabi Field, although other parts of the field revealed unloading mechanism.
\end{abstract}

Keywords: Compaction Trend; Crossplot; Elastic Impedance; Niger Delta; Overpressure.

\section{Introduction}

The knowledge of rocks or fluid attributes of a subsurface formation is vital in the study of the oil and gas Field. Therefore, understanding the nature of the rock formation is based on the measurement of petrophysical parameters such as porosity, saturations and permeability. Unfortunately, rock formations of a uniform and constant character are rare. The relationship between petrophysical parameters measured on core samples are often ill defined due to differences in conditions such as pressure, temperature and fluid changes. Although, all these conditions are put into consideration before drilling but pressure effect is one significant condition that should not be underestimated (Amongpantang 2010).The formation pressure is divided into three categories; normal, abnormal and subnormal formation pressure (Lopez and Rappold, 2001).The normal formation pressure describes the situation where formation pressure (pressure acting on the fluids in the pore spaces of the formation known as pore pressure) is approximately equal to the theoretical hydrostatic pressure (pressure in a column of formation water extending to the surface controlled by the density of the fluid) of a given depth. Abnormal and subnormal formation pressure represents pressure of a respectively higher or lower than this normal situation. These are caused by different mechanisms such as undercompaction, fluid expansion unloading, lateral transfer etc. Under compaction occur when there is increase in vertical stress during deposition of sediments, the pore fluid escape as the pore spaces try to compact. If a layer of low permeability material prevents the escape of pore fluids at rate sufficient to keep up with the rate of increase in vertical stress, the pore fluid begins to carry a large part of the load and pore fluid pressure will increase (Sayer, 2006). Fluid expansion loading mechanism occur when the rock matrix constrain the increased volume of the pore fluid that result from processes like heating, clay dehydration and hydrocarbon maturation (Dutta 2002) while lateral transfer mechanism occur when sediments under any given compaction condition has fluid injected into it from more pressure zone. However, as exploration of oil/gas extend to the deeper zones of the earth, this poses a great challenge as abnormal (higher) pore pressure are most likely to be encountered. These results in drilling problems such as blowout, kicks, borehole instability, stuck pipe, mud lost circulations among others. Therefore, a pre and post-drill prediction of pore pressure are essential for safe and economic drilling of wells in over pressured formation and this is the focus of this study. The overpressure variations in pre and post drilling processes in Fabi Field will be determined using elastic impedance inversion and sediment compaction trends. But for regions where secondary overpressure generation are present it could be quantified by integrating velocity versus density cross plot with understanding of basin history using comparative datasets. This is also a powerful tool of discriminating over pressure generating processes in the field. Therefore,to meet today's challenge of high drilling cost and to obtain accurate and quantitative pore pressure information, pore pressure analysts are to know the abnormal pressure causes and building a good model that could guide drilling processes.

\section{Location of the study area}

Fabi Field is located in Central swamp I in Onshore depobelt, located at about $35 \mathrm{~km}$ south-south of Greater Ugheli, Delta state Nigeria (Fig. 1.0). The area is situated on the continental margin of the Gulf of Guinea in West Africa at the Southern end of Nige- 
ria. It lies between Latitude $4^{\circ}$ and $7^{\circ} \mathrm{N}$ and longitude $3^{\circ}$ and $9^{\circ} \mathrm{E}$ bordering the Atlantic Ocean on the southern end of Nigeria. The northern boundary is the Benin flank and the North-eastern boundary is defined by cretaceous outcrop of Abakiliki High and southeastern end by Calabar flank. The province covers about $300,000 \mathrm{~km}$ and includes the geologic extent of the tertiary Niger delta (Akaka- Agbada) petroleum system. (Anakwuba et al, 2008, Aniwetalu and Anakwuba 2015, Onwuemesi and Egboka 2007)

\section{Materials and method}

Two basic data used in this study are well logs and 3D seismic data obtained from Fabi Field. The data were given with strict confidentiality for security reasons. Data interpretations and analyses were carried out using Hampson-Russel geophysical program.
The logs were despiked using media filtering in E-log module, to ensure that they contain only appropriate range of values. The media filtering operation replaces the sample value at the centre of the operator. The longer the operator length the smoother the log signatures. This process was largely experimental so as to isolate the best log operator length, we found that with an operator length of 25 , the logs were largely well smoothened. Fig.2.0a-b presents the non despiked and despiked well log through media filtering. The data were subjected to statistical wavelet extraction process. Statistical approach uses seismic traces alone to extract wavelet using Weiner- Levinson deconvolution process which uses autocorrelation function while the well log approach uses the $\log$ to determine the constant phase.

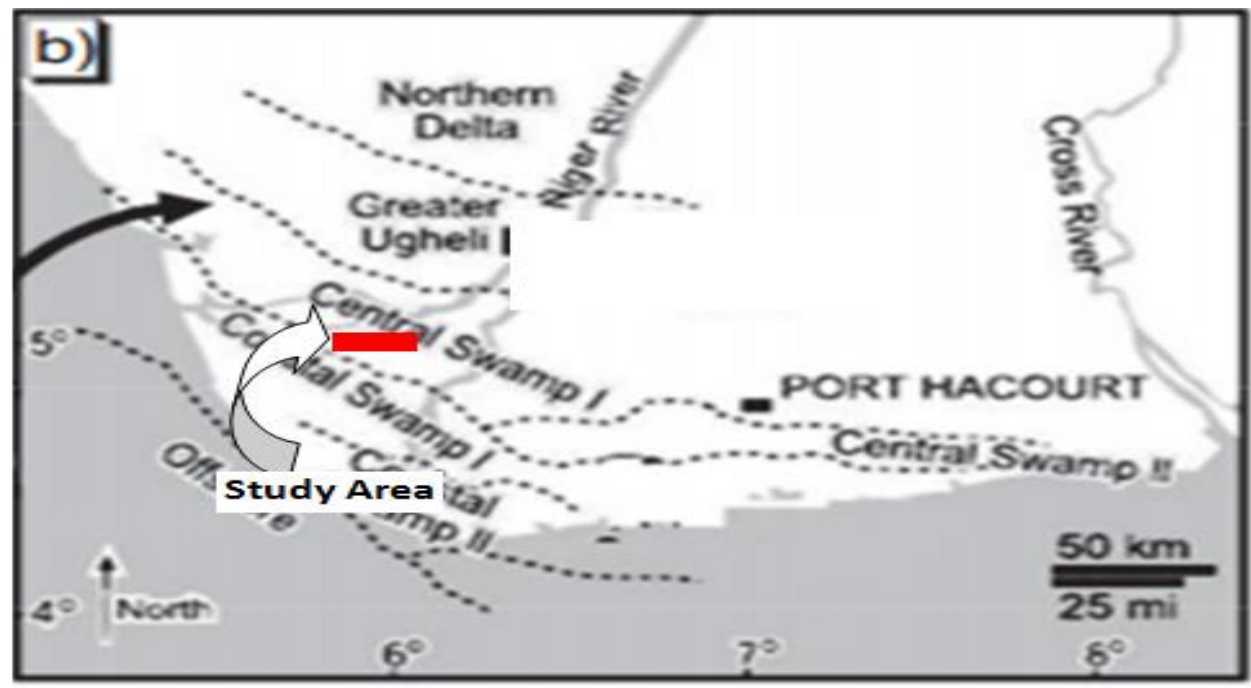

Fig. 1: Map of Niger Deltas Showing the Study Area.

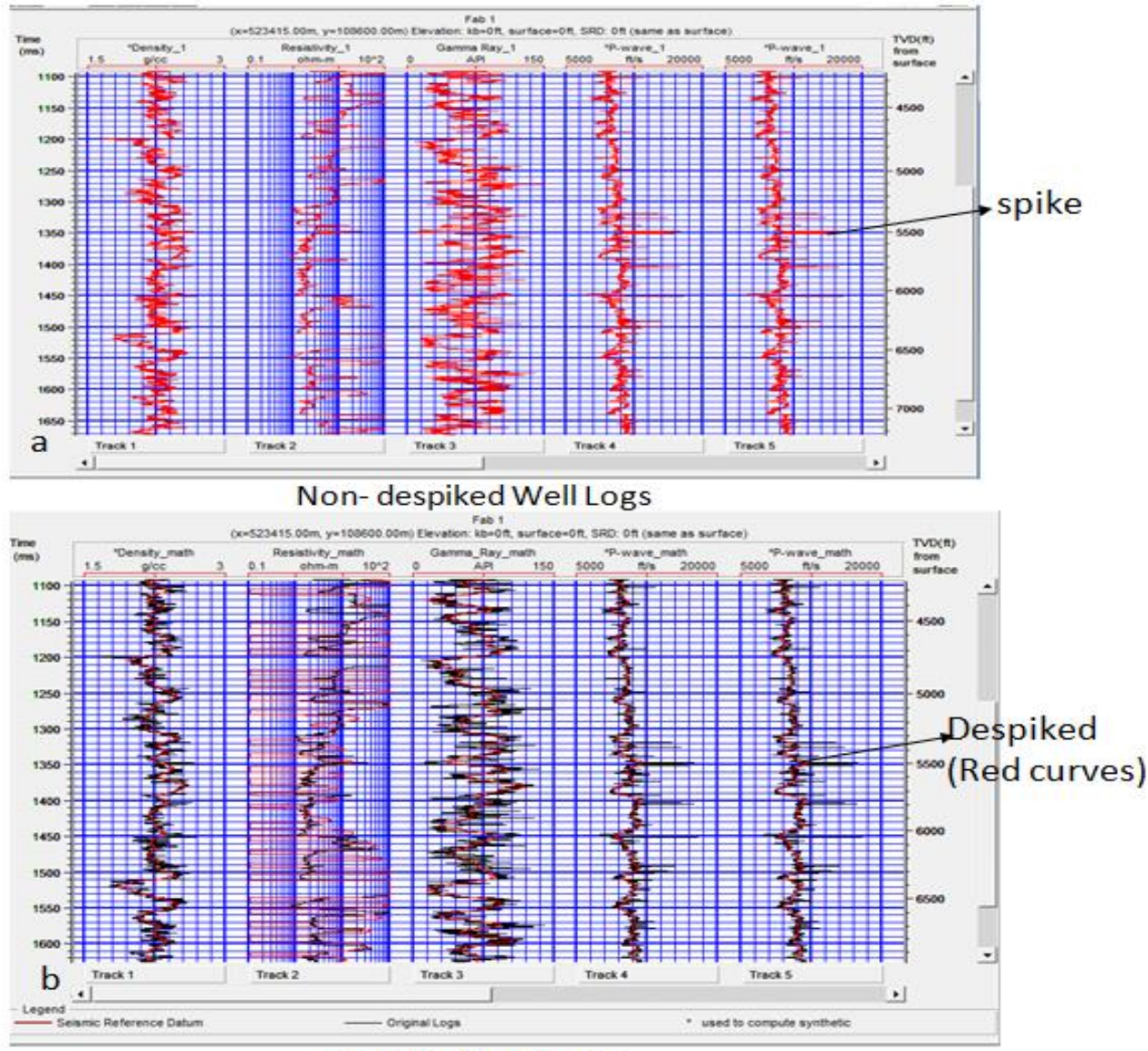

Despiked Well Logs

Fig. 2a-B: (A) Presents Original well logs with Spike and (B) Shows Despiked well logs (Red Curve). 
The aim is to obtain qualitative seismic to well calibration. Before the calibration, a fair depth time conversion was performed in order to make the vertical scale of the well acoustic impedance data match the vertical scale of the seismic data. This conversion was carried out using the sonic and the initial two ways travel time. The first sample provides the highest correlation coefficient between the synthetic and the observed trace. In this process, we manually stretch or squeeze the log and the seismic in order to improve the time correlation between the target logs and the seismic attributes. Once the needed bulk shift and stretches are applied, the well log depth to time map is expected to match the seismic times. This process simultaneously creates a composite trace from the seismic and synthetics seismogram from the log (fig $3)$.

Therefore, with data properly corrected for errors, the well logs were analyzed to determine the points of deviation from the compaction trends of the sediments. The pore pressure prediction points were picked from the clean shale depth interval while the measured points were in the sand (Fig.4).The normal compaction trend line and shale velocity trend line were also generated. With these trend lines, deviation from the normal compaction trends due to over pressure was obvious. Overpressure zones were detected at the depth points in which log signal pattern deviated from the trend line. However, the overpressure generating mechanisms were obtained from the crossplots of velocity and density logs. In seismic data, overpressure zones were estimated using model based seismic inversion techniques. The low frequency elastic impedance model was created. The model derived the impedance profile which fit the modeled trace and the seismic trace in a least square sense. The initial guess impedance is guided by well logs and horizons (TRK-2 and TRK-1) which defined certain depth of interest. The low frequency model was subjected to elastic impedance inversion in strata module of Hampson-Russel program. The overpressure variations in the field were interpreted based on the elastic impedance ranges of the inverted seismic volumes.

\section{Results and interpretation}

In well log overpresure analysis, the results showed normal compaction trends from depth level of $7200 \mathrm{ft}$ to $8625 \mathrm{ft}$. At depth level of about $8625 \mathrm{ft}$ to $9000 \mathrm{ft}$, the velocity, density and resistivity logs deviated from the normal compaction trends (Fig.5). As expected, velocity increases with depth for a normal pressure zone Golyan, (2012). It follows normal compaction trend of the sediment but when overpressure sets in, the velocity invariably slows down

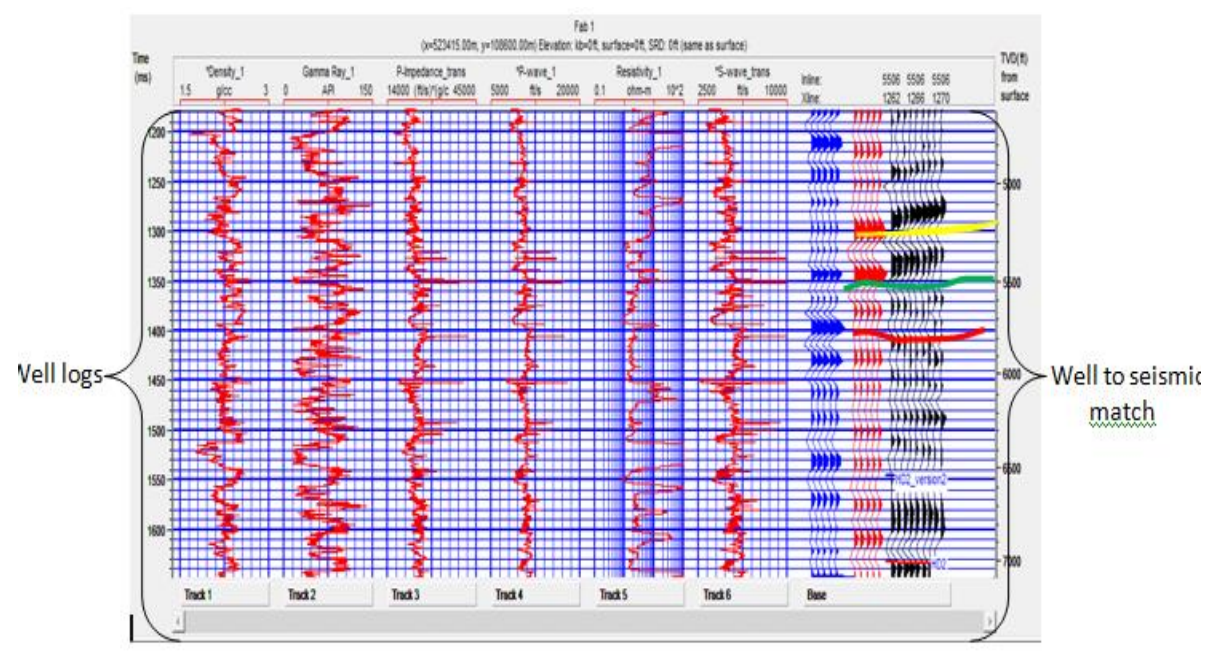

Fig. 3:Seismic to Well Tie of Fabi Field.

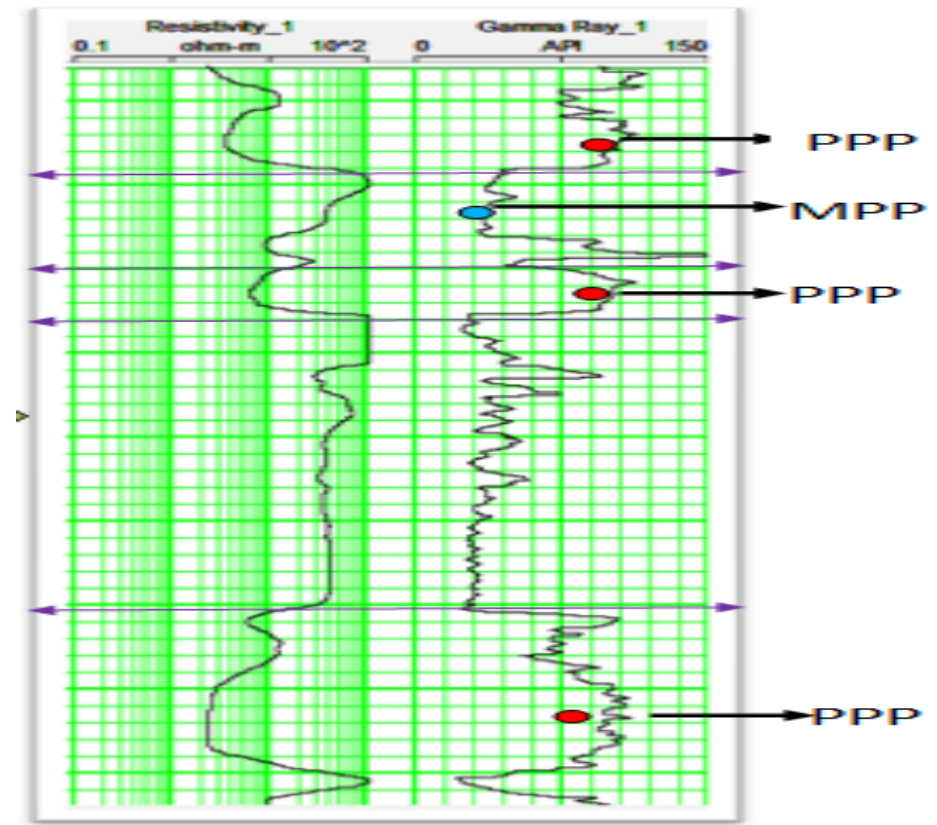

Fig. 4:Predicted Pore Pressure (PPP) Points Picked from Shale Depth Intervals (Red Dots) and Measured Pore Pressure (MPP) Points in the Sands (Blue Dots). 
And this is observed to fall below the normal compaction trend line (blue line) due to increase in porosity in the overpressure shale. The depth point where this change begins is known as the top of overpressure and this corresponds to about $8625 \mathrm{ft}$ as indicate by pink horizontal line (fig.5.0). Similar results were also obtained in the density and resistivity logs. The bulk density measurement is characterized by normal increasing trend with depth until the top of the overpressure zone is reached. In overpressure environments, the bulk density values are lower than normal trend value due to increased pore volume.Therefore, as rock compacts, the porosities are reduced in a normal pressure zones but increase in overpressure zones, due to the inability of the pore fluid to escape in equilibrium with the rate of the compaction. In similar manner, shale resistivity increases with depth but deceases when it encounters overpressure zones. It decreases due to the relative change in the mineralogy whereby the illite part increases at the expense of the montmorillonite part of the clay structure, leading to high conductivity.

Specifically however, in Fabi Field, different mechanisms cause rocks to be overpressured and their overpressure behavioral pattern varies. Therefore, with cross-plots of velocity and density, two overpressure generating mechanisms were identified in the field and interpreted as under-compaction and unloading effects
(Fig.6a-b). The under compaction is characterized by both decrease in velocity and density (Fig.6a). In this case, with increase in vertical stress, the pore fluids escape as rock pore spaces try to compact. If a layer of low permeability material prevents the escape of pore fluids at rates sufficient to keep up with the rate of increase in the vertical stress, the pore fluids begin to carry a large part of the load and the pore fluid pressure increase. In unloading mechanism, there is abrupt decrease in velocity and at constant change in density. In this case, velocity -density plot recognized unloading mechanisms characterized by abrupt decrease in velocity at a constant density (Fig.6b).

The elastic impedance inversion of the seismic data presents the lateral variations of the overpressure zones in the Fabi Field (Fig.7).The yellow oval indicates the onset of overpressure formation which corresponds to about $1920 \mathrm{~ms}$. The red ovals indicate overpressure zones in the field which become dominant at about 1940-1140ms corresponding to very high impedance value of about $25540-27067 \mathrm{ft} / \mathrm{s} * \mathrm{~g} / \mathrm{cc}$. The over-pressure zones are identified as high elastic impedance zones (pink color code) and it extends laterally beyond 1294 cross line point in the right and below the 1238 cross line in the left.

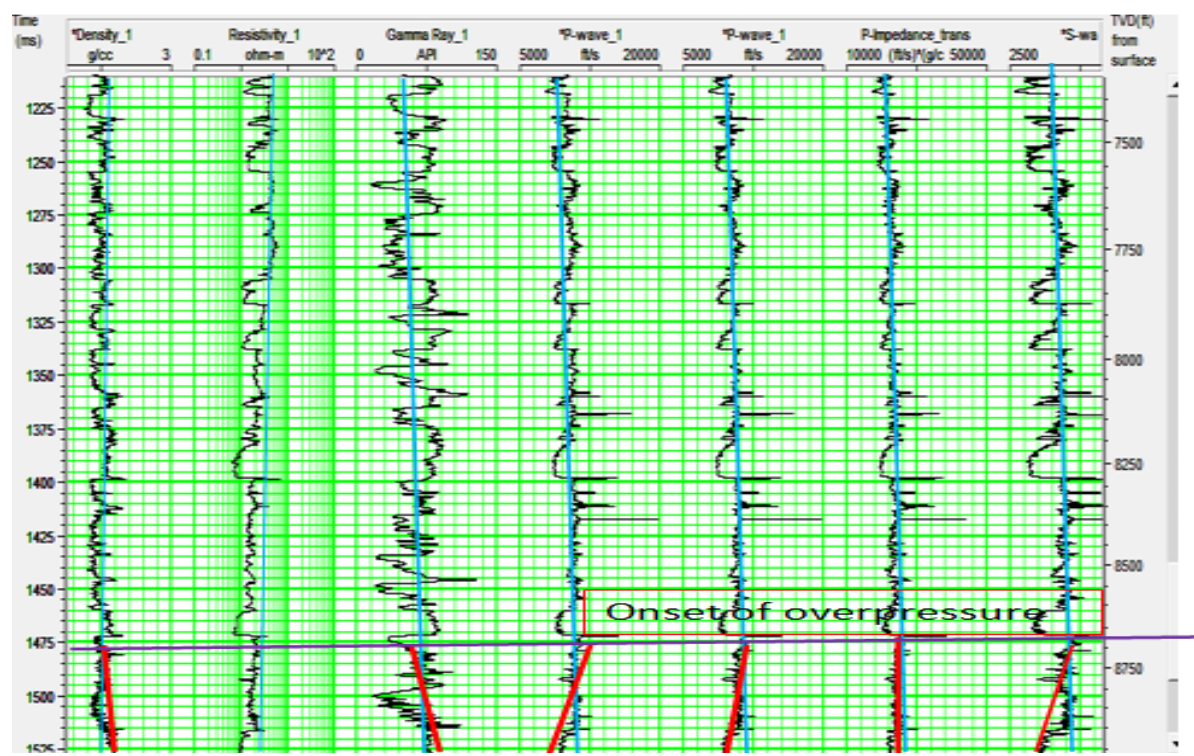

Fig. 5:Normal Compaction Trend Line (Blue Line) of Well Logs Indicating Onset of Overpressure Zone (Red Line).

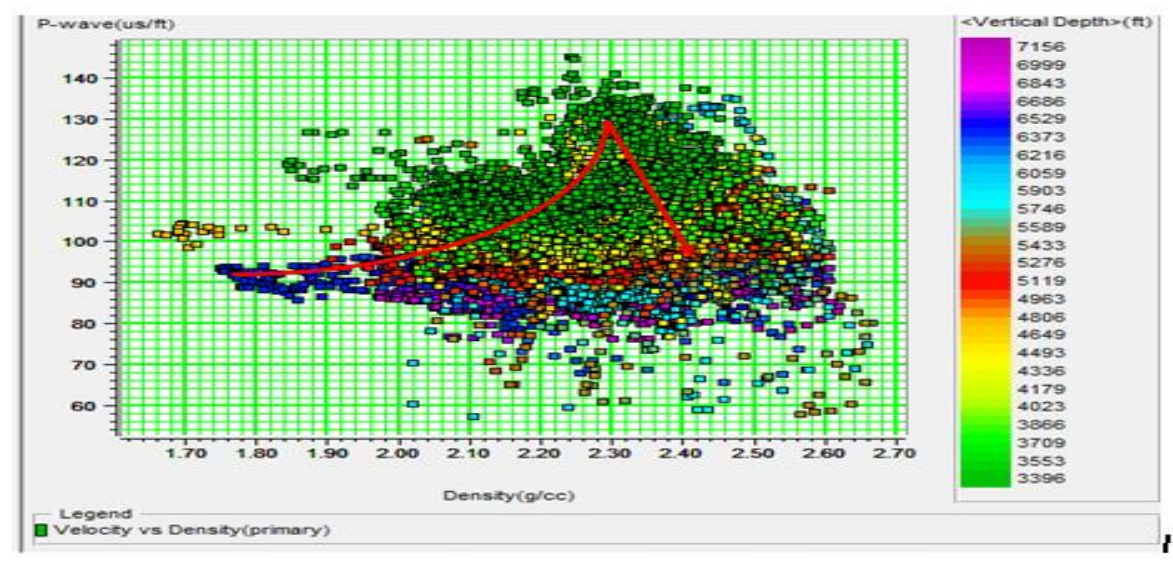




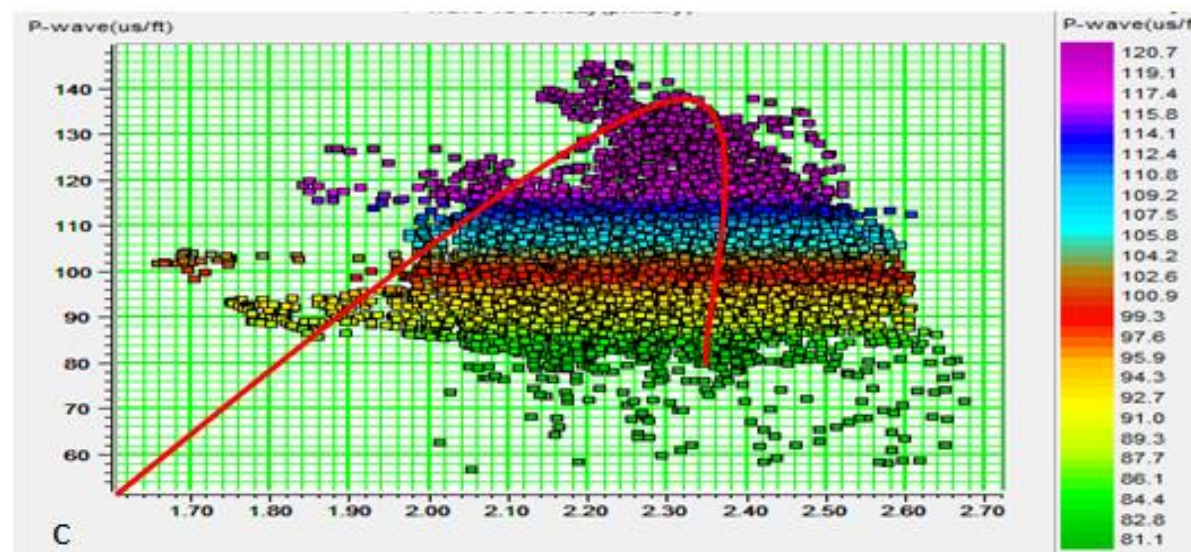

Fig. 6a-C: (A)Velocity-Measured Depth and (B) Density-Measured Depth Crossplots Recognizing Decrease in Velocity and Increase in Density with Depth Indicating Over Pressure (Identified Via Color Codes) (C) Velocity -Density Plot Recognizing Unloading, Characterized by Abrupt Decrease in Velocity at A Constant Density (Identified Via Color Codes).

In elastic impedance inversion, the area extents of the positive (increase in elastic impedance) anomalies are mostly consistent with the pressure while low acoustic impedance is interpreted as reservoir or sand zones indicated by green and yellow color codes.Generally, velocity increases with depth for normal pressure zone but when overpressure sets in, the velocity invariably slowdown resulting to a fall below the normal trend, but acoustic impedance derived from the product of velocity and density increases with increase in overpressure. Therefore, elastic impedance through inversion uses the relationship between density and velocity to predict the pore pressure variations by converting the seismic reflectivity data into quantitative rock properties that are descriptive of the Formation. The overpressure variations in the other parts of the seismic data were also evaluated through analysis of pressure cube taken along a particular horizon of interests. Fig.8 presents overpressure cube taken along the TRK-2 and TRK-1 horizon. Very high elastic impedance interpreted as overpressure zones (red oval) is observed around the well trajectory in the southeastern part of the cube. The yellow oval indicates overburden pressure known as total vertical stress which combined the weight of the rock matrix and the fluids in the pore spaces overly- ing the horizon. The histogram plot (TRK-2 and TRK1 horizon) presents the rate of overpressure distributions within the horizons (Fig.9). The pressure trend agrees with the well control which recognized overpressure at approximately $8625 \mathrm{ft}$ to nearly $9000 \mathrm{ft}$. In seismic data analysis, mild overpressure was estimated between 1560ms -1600ms (TRK-1 and TRK-2 horizon), then the hard overpressure was estimated between $1940 \mathrm{~ms}$ - 2120ms corresponding to about $25540-27067 \mathrm{ft} / \mathrm{s} * \mathrm{~g} / \mathrm{cc}$.

\section{Conclusion}

Overpressure variations in the Fabi Field onshore Niger delta have been investigated using well log and seismic data. Zones of overpressure was evaluated from the deviations from normal compaction trends using well logs at depth level of $8625 \mathrm{ft}$ to $9000 \mathrm{ft}$. The velocity and density crossplots showed the main overpressure generating mechanism in Fabi Field is undercompaction, although other parts of the field revealed unloading, as its cause of overpressure.

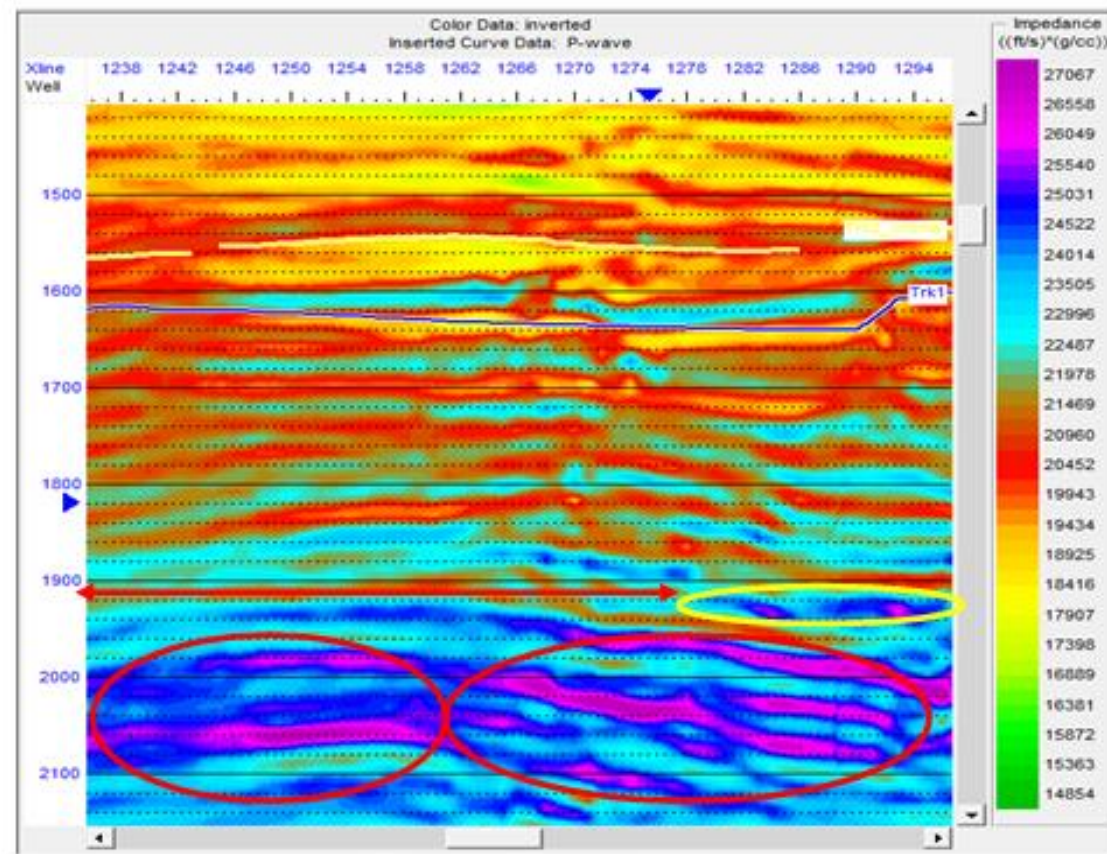

Fig. 7: The Inverted Acoustic Impedance Volume Showing Overpressure Variations in the Field. 


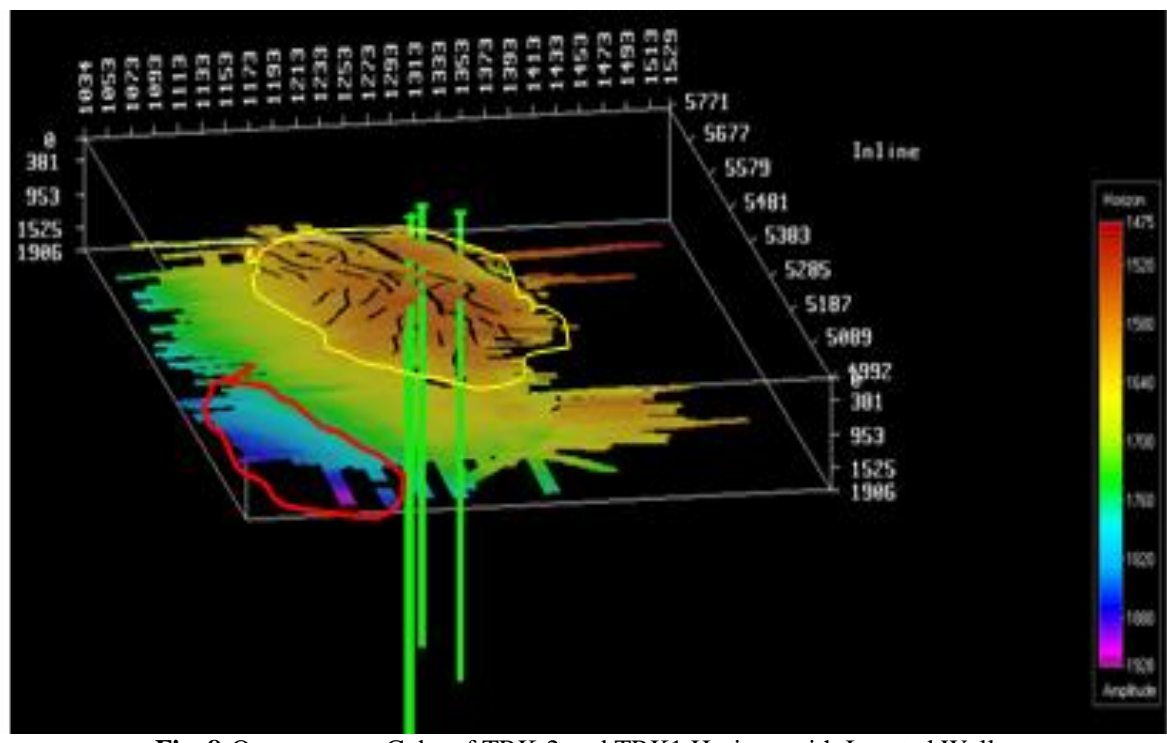

Fig. 8:Overpressure Cube of TRK-2 and TRK1 Horizon with Inserted Wells.

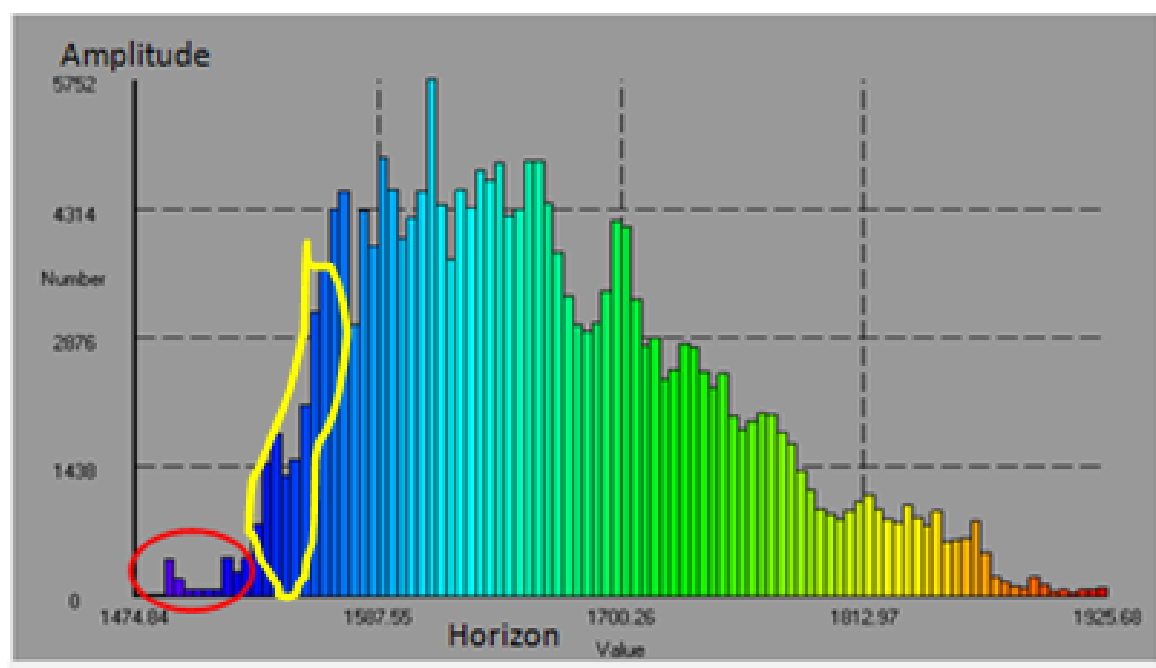

Fig. 9:The Histogram Plots of TRK-2 and TRK1 Horizon Showing Rate of Overpressure Distributions.

Away from the well control points. Therefore, hard overpressure zones were encountered at about $1940-1140 \mathrm{~ms}$ corresponding to very high impedance value of about $25540-27067 \mathrm{ft} / \mathrm{s} * \mathrm{~g} / \mathrm{cc}$. these overpressure zones also extend laterally beyond the bounded xline of the elastic impedance profile. Mild overpressure was also estimated from the seismic data between $1560 \mathrm{~ms}-1600 \mathrm{~ms}$ within the TRK-1 and TRK-2 horizon which also correspond to the well control points to about $8625 \mathrm{ft}$ to nearly $9000 \mathrm{ft}$. The overpressure trend in the horizon and the histogram plot presents the overpressure trends and distributions within the horizons respectfully. Therefore, since overpressure poses a significant risk to drilling process, using multiple methods can increase the confidence in the prediction.

\section{References}

[1] Anakwuba, E.K., Onwuemesi, A. G., Ajaegwu, N. E, .Akpunonu, E.O and Onuba, L.N., (2008). Sequence stratigraphic approach in hydrocarbon exploration of Diok Field, Eastern Niger Delta. Natural and Applied Sciences Journal, .9(1) 41-50.

[2] Aniwetalu E. U. and Anakwuba E.K., (2015). Quantitative Characterisation of Groundroll (Rayleigh Waves) in the Western Niger Delta, Nigeria. Archives of Applied Science Research, Vol.(4), P. 7-22

[3] Amonpantang, P. (2010). An overpressure investigation by sonic $\log$ and seismic data in Morgot Field, Gulf of Thailand: Bulletin of earth sciences of Thailand Vol.3. No 2. P. 37-40.
[4] Dutta, N.C. (2002). Deep water geohazard prediction using Prestack inversion of large offset $\mathrm{P}$ wave data and rock model: Western Geco, Houston Texas, U.S. The leading Edge P.193-198.

[5] Golyan, M.F., (2012); Compaction, rock property evolution and rock physics diagnostics of Askeladd discovery, Norwegian Barents Sea; Master thesis (Masteroppgave). P 50-58.

[6] Lopez, J and Rappold, P.M (2001).Wieseneck 3D pressure prediction intergration of geophysical, geological and petrophysical data and analysis.

[7] Onwuemesi, A.G. and.Egboka, B. C. E, (2007). Petroleum prospects of the Anambra Basin.

[8] Natural and Applied Sciences Journal, Vol. 8, (1), P.1-7..

[9] Sayer,C.M (2006). An introduction to velocity based pore pressure estimate;Schlumberger Data and consulting services, Houston, U.S.A. The Leading Edge; V.25 (12) P.1496-15000 SEG.http://dx.doi.org/10.1190/1.2405335. 